\title{
Manifestation of kubanga causal connectives in English-Luganda bilingual discourse
}

\author{
Sarah Nakijoba
}

Department of Linguistics, English Language Studies and Communication Skills, Makerere University, Uganda Department of General Linguistics, Stellenbosch University, South Africa

Email: kalyangon10@gmail.com; snakijjoba@chuss.mak.ac.ug

\begin{abstract}
This article presents an overview of the Luganda causal marker kubanga (because) as it occurs in a bilingual Luganda-English spoken discourse. I explore the general structural and functional status of kubanga forms by describing their occurrence in bilingual utterances, explain their context-dependent causal roles and point out their domain specificity. The analysis of data is informed by Myers-Scotton's (1993, 1995, 2002) Matrix Language-Frame model (MLF), a model which explains the structural configurations of embedded elements within bilingual clauses and Sweetser's (1990) domain of use model to account for the domain specificity of these forms. Reference will also be made to recent developments in the works on causality (in which the domain model has been reanalysed in terms of Objectivity and Subjectivity). I also make reference to Blakemore's (2002) Relevance theory-based notion of conceptual-procedural encoding. The findings show that a kubanga form can occur as a single word inserted in an expression which is entirely in English, it can occur in mixed constituents and a kubanga clause can occur as an island. It is evident that kubanga forms operate in four domains (content, epistemic, speech act and metalinguistic) and that they are domain specific. Kubanga forms are positionally mobile and can occupy the initial, medial and final positions in their host clauses.
\end{abstract}

Keywords: Causality; Kubanga; Luganda; domain of use; Matrix Language frame model.

\section{Introduction}

This study examines the Luganda causal marker kubanga (because) as it occurs in a bilingual Luganda-English spoken discourse. Kubanga is one of the most common devices used to encode causal relations in Luganda, a Bantu language spoken in Central Uganda. In this language, kubanga occurs in 12 causally related forms: kubanga (because), kuba (because), kulwokuba (for the reason that), kulwokubanga (for the reason that), lwakuba (because), lwakubanga (because), olwokubanga (because of/since/for the fact that), olwokuba (because of/since/for the fact that), and the two infrequent pairs okuba/okubanga, and bba/bbanga, all translatable roughly as because. Note that each of these kubanga forms is a fully-fledged independent element and would resist semantic decomposition. In the bilingual study data, only seven forms manifest, namely, kubanga, kuba, olwokuba, olwokubanga, kulwokuba, lwakuba, 
and lwakubanga. Out of the seven, only four forms are analysed: kubanga (because), kuba (because), olwokubanga (because of/since/for the fact that), and olwokuba (because of/since/for the fact that) because they are the only forms which occur in bilingual clauses. For simplicity of expression, I adopt the expression "kubanga form" in reference to any of the variations of kubanga in the analysis. The choice of the expression "kubanga form" is motivated by its high occurrence in the data, in comparison to other forms.

The prototypical kubanga form is contentious; consultants do not seem to agree on which form out of the twelve is the proto form. Whereas the majority of Luganda speakers consulted in this regard point to kubanga for the reason that it is underspecified and can occur in all domains of use, some consultants propose kuba. Considering the seemingly related forms of the kubanga pragmatic markers (PMs), it is tempting to assume that kubanga, olwokuba, olwokubanga, lwakubanga, lwakuba, and so on, are morphological derivations from the form kuba, as underlined. However, this assumption is yet to be empirically justified. In addition, given the frequency in the use of $k u b a$ it might have undergone phonological reduction, becoming a contracted form of kubanga (kuba) and olwokubanga (olwokuba). The way kuba operates is similar to the English informal contraction 'cause or the Swahili sababu (from kwa sababu). However, whereas 'cause and sababu are informally used, kuba is formal. A further discussion of kuba may be interesting but it is beyond the scope of this study. Note that kuba serves other grammatical roles which are not causally related. For example, kuba occurs as a polysemous intransitive verb or verbal phrase in, kuba (beat), kuba (draw), kuba akalulu (cast a vote), kuba ekigwo (wrestle), kuba omulanga (appeal), etc. Kuba can also serve auxiliary verbal functions such as, lwa kuba muwanvu naye muto (she is tall but young); it occurs in rhetoric and interjected constructions e.g. lwa kuba maama! (how I wish?). Such roles should not be confused with the procedural causal roles it plays.

The Luganda orthography is contentious, and such orthographic discrepancies are evident from the way kubanga forms are spelled, namely, as olwokuba or as olw'okuba, lwakubanga or lw'akubanga, and so on. These differences are evident in documents written in a Standard Luganda variety including the Luganda Bible and in Luganda novels written in early 1970s. However, the adopted spelling for a given form does not affect its semantic or pragmatic (causal) qualities. Besides, such variations are evident in written but not spoken language. By preference, all the forms analysed in this article are spelled without an apostrophe.

In this article, kubanga forms are analysed operating in four domains, namely, the content, epistemic, speech act and metalinguistic domains. At the content level, kubanga relates to the objective causality where it associates clauses in which the cause and effect between subordinated clauses is demonstrated. At the epistemic level, a kubanga form encodes causality by offering justification/reason for the existence of an event. At the speech-act level, a kubanga clause prefaces the speaker's motivation for performing a speech act. And at the metalinguistic level, the relation encoded by a kubanga form is more conversational than correlational. In this analysis, kubanga forms are construed as PMs by virtue of their ability to facilitate interaction by providing clues to the hearer which constrain the inferential process of utterance interpretation. Following the Relevance theoretic framework (Sperber and Wilson 1995) in which it is argued that human cognition is relevance oriented, clauses without a kubanga connective would remain fully propositional if processed in the right context. However, the advantage of clauses conjoined with kubanga are easier to process because the connective encodes procedures which guide the hearer to the most relevant interpretation, and thereby 
reduce the processing cost (Blakemore 2002: 79). Similarly, studies have reported that because clauses increase processing efficiency in utterances where they occur by providing "a simpler route, reducing the number of inferential steps and helping to determine semantic and pragmatic contents such as entailments, explicatures and implicatures" (Moeschler 2016: 122). They also "speed up the processing of the words immediately following the conjunction" (Cozijn, Noordman, and Vonk 2011: 475), "provide processing instructions" (Canestrelli, Mak and Sanders 2013), and "explicitly signals the reader to integrate the two clauses together" (Millis and Just 1994: 128).

In general, kubanga PMs have not been studied far beyond reference to them in dictionaries and a few classic online resources, dating as far back as the 1920s. The classic works were mainly authored by European scholars during the colonial era, in collaboration with native Luganda speakers, most of whom were non-linguists. Whereas I acknowledge the contribution of such resources to the body of literature, these findings need to be supplemented by detailed authentic descriptions, and theoretical analyses of this kind. For lack of satisfactory literature on kubanga forms, their analysis in this study is partly based on the findings of cross-linguistic studies, in addition to the introspective views from language consultants and assumptions inferable from the behaviours of kubanga PMs in the data. However, comparing kubanga PMs with other causal markers in languages such as English, Modern Greek and French did not provide a linear comparison because languages differ in the number of entries used as causal PMs, and in their domain specificity. Besides, the methodologies used in the analysis of the causal markers in cross-linguistic studies and the size of data sets differ greatly.

In this article, I argue that an examination of kubanga causal markers is essential in contributing towards a general understanding of how causality is encoded in less studied languages such as Luganda. It will also contribute towards establishing the behaviour of causal PMs in contact situations. Although I do not attempt to analyse kubanga forms holistically, the findings in this study are part of the foundation on which recommendations for further studies can be laid. The article is divided into 8 sections. Section 1 features the introduction which provides the background of the study, Section 2 presents the methodological dimensions of data collection and analysis including the nature of data described, Section 3 discusses frameworks adopted in the analysis of kubanga PMs; Sections 4, 5, 6, and 7 feature the discussion and analysis of data in light of the study objectives. Finally, Section 8 serves as the conclusion/recommendation.

\section{Methods and nature of data}

The kubanga forms analysed in this article are extracted from the Luganda-English bilingual spoken corpus which was collected in 2015. The 192000 word corpus was obtained from verbatim transcriptions of 23 hours of audio recordings of code switched conversational interviews and discussions from forty-one adult male and female participants, all working or studying at Makerere University. They were assumed to have had adequate experience with English, and are able to comfortably engage in classic code switching by employing resources from both languages during bilingual communication. The interviews and discussions were semi-formal and, using a semi-structured interview guide, participants shared their experiences and views on casual topics, such as childhood experiences, sociolinguistic profiles, language attitudes and ideologies. Group discussions lasted for between 60-120 minutes, giving each participant an average of 19 minutes of interaction. The face-to-face interviews lasted between 
30 and 70 minutes. The Luganda segments in the selected excerpts for analysis were translated and glossed using word-for-word, and morpheme-by-morpheme glossing notation, as need arose.

The corpus is highly code-switched, with kubanga PMs forming an interesting part of the embedded constituents. As mentioned, not all twelve forms of kubanga are exhibited in the data, only seven are. They include kubanga, kuba, olwokubanga, olwokuba, lwakuba, lwakubanga and kulwokubanga, as shown in Table 1. However, not all seven forms occur in bilingual clauses, only four do, and they include kubanga (because), kuba (because), olwokubanga (because of/since/for the fact that), and olwokuba (because of/since/for the fact that), as shown in Table 2. In summary, there are 684 tokens of kubanga forms in the data of 192000 words and 81 of these tokens occur in bilingual clauses.

\begin{tabular}{|l|l|l|l|l|l|l|l|}
\hline Study data & kubanga & kuba & olwokubanga & olwokuba & lwakuba & lwakubanga & kulwokuba \\
\cline { 2 - 7 }$(192,000$ & 316 & 277 & 15 & 36 & 29 & 10 & 1 \\
words $)$ & $(46 \%)$ & $(40 \%)$ & $(3 \%)$ & $(5 \%)$ & $(4.2 \%)$ & $(1.5 \%)$ & $(0.2 \%)$ \\
\hline
\end{tabular}

Table 1: Distribution of kubanga PMs across data

\begin{tabular}{|l|l|l|l|l|}
\hline X out of 81 & kubanga & kuba & olwokuba & olwokubanga \\
\cline { 2 - 5 } (occurring in bilingual clauses) & 50 & 22 & 3 & 6 \\
\hline
\end{tabular}

Table 2: Distribution of kubanga PMs in bilingual clauses

The differences in the distribution are briefly explained under the discussion on domain specificity of kubanga PMs in Section 7.

\section{Theoretical framework}

As mentioned, data in this article will be analysed within Myers-Scotton's $(1993,1995,2002)$ Matrix Language-Frame model (MLF), Sweetser's domain of use model (1990), in addition to Blakemore's (2002) conceptual vs procedural encoding. These three are briefly described in the following sections.

\subsection{The Matrix Language Frame}

Myers-Scotton's (1993, 2002) Matrix Language Frame (MLF) model, including the supporting Four types of Morphemes Model (4-M model), is a frame-based model of grammatical constraints, aimed at explaining the structural configurations found in intra-sentential CS - CS in which morphemes from two or more language varieties occur in the same clause. Following certain principles and premises, the model predicts the possible occurrences of well-formed bilingual clauses, and in this paper, the model is aligned to account for the structural configurations of kubanga forms as exhibited in the Luganda-English bilingual utterances.

The claims of the MLF model are built on the principle of asymmetry: both structural and lexical. Structural asymmetry relates to the roles of the participating languages in the bilingual clause and lexical asymmetry relates to the grammatical constraints on what morpheme types 
come from what language in the bilingual clause (Myers-Scotton 2002: 9). The first premise under structural asymmetry relates to the Matrix Language hypothesis which assumes that languages which constitute the bilingual constituent do not participate equally (Myers-Scotton 2006: 243). The dominant language, the Matrix Language (ML), has a more central role of providing the grammatical/morphosyntactic frame in the bilingual clause and the less dominant language, the Embedded Language (EL), contributes the switch. The assumption is that wellformed bilingual structures, the ML+EL constituent, and their configurations are ML- rulegoverned. By proposing the Uniform Structure Principle (USP) ${ }^{1}$, paraphrased as "no chaos allowed", the principle defines what should and what should not occur in a well-formed constituent (Myers-Scotton 2002: 8). It assumes that languages are conditioned towards uniformity and they strive to achieve it. Thus, in classic CS the grammatical structure of the ML will always be preferred and the EL are allowed on the condition that they observe the well-formedness conditions of the ML (Myers-Scotton 2006: 243).

For instance, in bilingual utterances (1) and (2), both Luganda and English are participating in contributing morphemes to the bilingual clauses. However, their participation is not equal. To signal causal relations in utterance (1), AS inserts an EL switch, $k u b a$, in a clause that is otherwise all in English. Similarly, in utterance (2), NS inserts an English because in a sentence that is otherwise all in Luganda. Thus, in utterance (1), the ML is English as it provides the grammatical frame of the sentence and Luganda is therefore the EL because it supplies the kuba switch. In sentence (2), the ML is Luganda and English is the EL which supplies the switch, because.

Er I think back in 2002 kuba I was in P.2, ... (AS2)

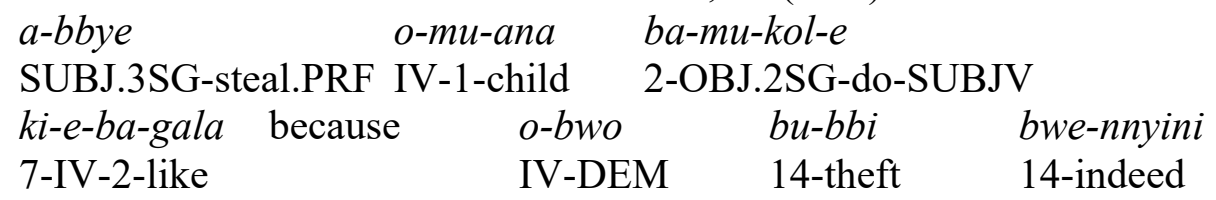

"A person who has stolen a child should be punished as they (arresters) wish because that is criminal theft." (NS85)

The ML is not determined arbitrarily but it is determined following two principles, the Morpheme Order Principle (MOP) and the System Morpheme Principle (SMP).

The MOP states that,

in Matrix Language + Embedded Language constituents consisting of singly occurring Embedded Language lexemes and any number of the Matrix Language morphemes, the surface morpheme order (reflecting surface syntactic relations) will be that of the Matrix Language (Myers-Scotton 2002: 59).

The SMP, on the other hand, states that,

in the Matrix Language - Embedded Language constituents, all system morphemes which have grammatical relations external to their head constituent (i.e. which participate in the sentence's thematic role grid) will come from the Matrix Language (Myers-Scotton 2002: 59).

The two principles ensure that a language that satisfies the requirements contained in the MOP and SMP will be the ML.

\footnotetext{
${ }^{1}$ USP states that, "[a] given constituent type in any language has a uniform abstract structure and the requirements of well-formedness for this constituent type must be observed whenever the constituent appears" (Myers-Scotton and Jake 2009: 337).
} 
While the identification of the ML might be transparent in certain bilingual clauses, such as in (1) and (2) above, there are constructions where the identification of the ML requires deeper engagement with the MOP and SMP, as we see in utterance (3).

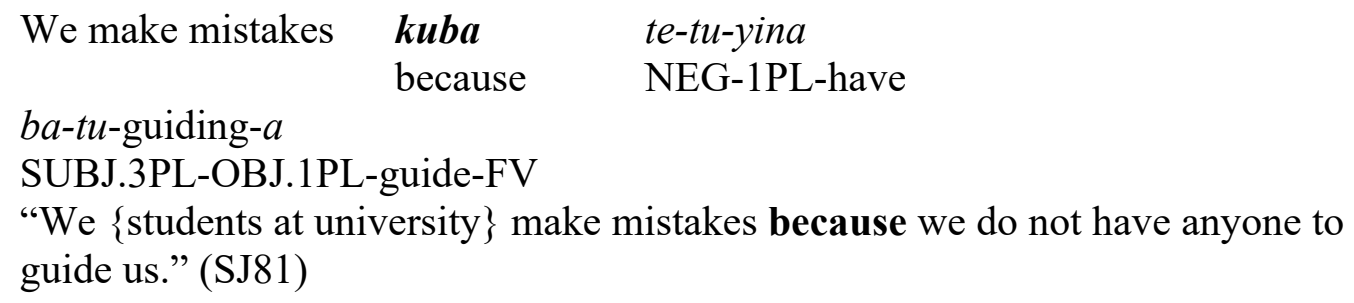

"We \{students at university\} make mistakes because we do not have anyone to guide us." (SJ81)

This bilingual construction has two clauses: the EL island (we make mistakes) and a bilingual clause (kuba tetuyina batuguidinga (because we lack people to guide us)). As mentioned, the MOP ensures that the word order of the bilingual clause conforms to the word order of the ML. Note that the morpheme ordering of constituents in Luganda and English is the same, given that Luganda and English share the canonical word order of sentences, the SVO (Subject, Verb, Object) structure. By applying the MOP criterion, you find that the ML in example (3) can be Luganda or English. However, by applying the second principle, the SMP, we establish that the ML as Luganda for SMP requires that in mixed constituents, system morphemes will come from the ML. The form batuguidinga is a morphologically integrated switch which conforms to the agglutinative nature of Luganda morphemes. Resumptive pronouns such as $b a$-(which co-indexes with the counsellors) and $t u$-(which co-indexes with the students) in the form batuguidinga also mark agreement with their antecedents. Following the 4-M model, see Figure 1 below, morphemes which mark agreement are categorised as late outsider system morphemes and these are conditioned to come from the ML.

The second premise of the MLF model relates to the participation of morpheme types in the bilingual clause. Within the model, morphemes are categorised according to the content-system morpheme distinction, which corresponds roughly to other syntactic dichotomies such as free - bound morphemes, open - closed class words, content - function words, lexical grammatical items, and so on. The assumption is that not all morphemes can come equally from the ML and the EL (Myers-Scotton 2006: 423). In the bilingual clause, for instance, content morphemes can be supplied by both the ML and the EL but certain types of grammatical elements (system morphemes) can be supplied only by the ML. Figure (1) displays the classification of morphemes according to the 4-M Model. 


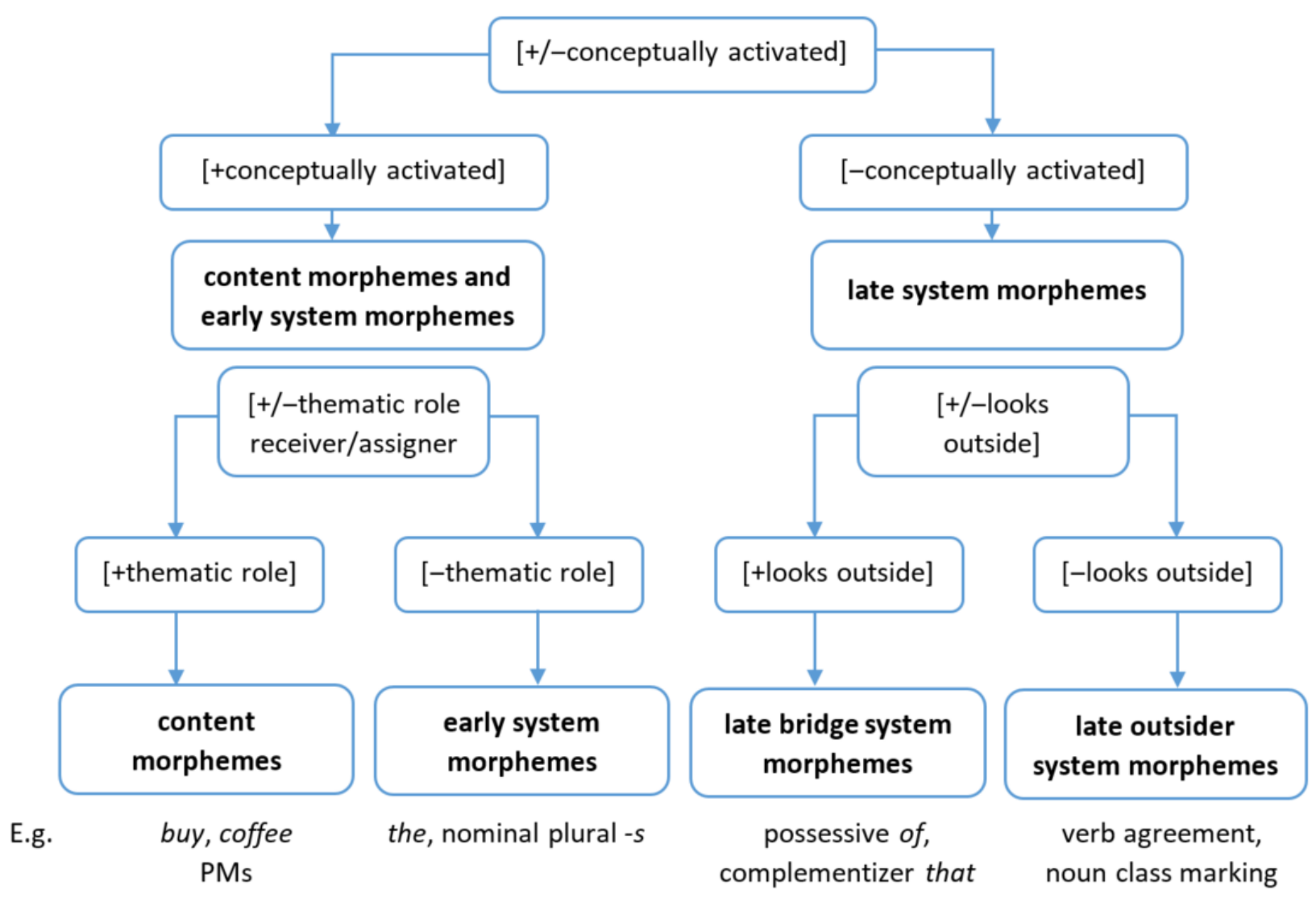

Figure 1: Feature-based classification of morphemes in the 4-M model (Myers-Scotton 2002: 73)

It should be noted that within the MLF model, PMs such as kubanga (discourse markers therein) are awarded the status of content morphemes for the reason that they are conceptually activated and assign thematic roles at the discourse level (Myers-Scotton 1995: 241; Myers-Scotton and Jake 1995: 984). Like ordinary content morphemes, such as verbs which assign theta roles such as Agent, Patient and so on, the discourse thematic roles assigned by PMs may include Topic, Focus or Consequence (Myers-Scotton 2002: 241). In utterance (4), naye (but) assigns contrastive discourse thematic roles just as kuba assigns the validation roles (see Myers-Scotton 2002: 241).

$$
\begin{array}{lllll}
\text { hmm naye } & k i-a-n-p i s-a & b u b i & \text { nnyo } & \text { kuba } \\
\text { yes but 7-PST-SUBJ.1SG-treat-FV } & \text { bad } & \text { very } & \text { because } \\
\text { I used to cry every day } & & &
\end{array}
$$

"But it \{studying in a boarding school\} affected me so much because I used to cry every day." (HK165)

The third premise relates to the activation of participating languages involved in CS. The MLF model assumes that when a speaker engages in CS, the participating languages are always "on", although the ML is always more activated (Myers-Scotton 2006). However, Myers-Scotton (2006: 423) recognises that whereas the MLF model can empirically support the first two premises (regarding the ML - EL opposition and content - system morpheme opposition), it doesn't provide heuristic support for the premise of 'activation'. Nonetheless, she points out 
that the patterns of CS can offer strong indirect support for the levels of 'activation' in the participating languages.

\subsection{Domains of use theory (Sweetser 1990)}

Sweetser's (1990) domain of use theory offers an explanation to the interpretive ambiguities between utterances encoded by identical causal connectives such as because. She proposes that the meaning of causal connectives should be interpreted "in context of an utterance's polyfunctional status as a bearer of content, as logical entity, and as the instrument of a speech act" (Sweetser 1990: 76). Thus, her analysis demonstrates that because in (5.a-c) operates along three functional domains: content, epistemic and speech act domain respectively.
a. John came back because he loved her, [P because Q].
b. John loved her, because he came back, [because Q, I conclude/infer P].
c. What are you doing tonight, because there's a good movie on ${ }^{2},[\mathrm{I}$ ask $\mathrm{P}$, because Q].

In the content domain in (5.a), because encodes a real-world cause-consequence relation in which John's love for her was the real cause of his coming back. In the epistemic domain in (5.b), John's return is interpreted as a premise for the conclusion that John loved her. Epistemic uses may be correlational but realistically, his coming back is not the cause of his love for her. In the speech act domain in (5.c), the because-clause prefaces a directive and justifies the speaker's motivation for performing a speech act (see Sweetser 1990: 77). Note that Sweetser, on the basis of cross-linguistic data, makes reference to the possibility of the existence of a fourth domain, namely the metalinguistic domain which I illustrate later in Section 6.4.

By extension, if the Luganda kubanga replaced the English because in utterances $(5 \mathrm{a}-\mathrm{c})$, the Luganda-English bilingual utterances would receive similar interpretative value. What is evident from the three utterances is that in the content domain, PMs relate utterances at propositional level, and in the epistemic and speech act domain, they relate utterances by the speaker's reasoning, explanation, and justification among others. For this reason, utterances which express direct causality in the content domain are processed faster than their counterparts (Noordman and de Blijzer, 2000: 38). In addition, while utterances in the content domain are compatible with comma and commaless intonation patterns, the epistemic or speech act domain uses always receive a comma intonation pattern (Sweetser 1990: 83).

Note that recent studies have revisited the Sweetser's domain of use theory categories and a new categorisation of causal connectives has been proposed, namely, the objective and subjective distinction, and has been adopted in cross-linguistic studies (see Stukker and Sanders 2012; Sanders, Sanders, and Sweetser 2012; Sanders and Spooren 2015; Zufferey 2012). In this analysis, I make reference to this new categorisation.

\footnotetext{
${ }^{2}$ Sweetser (1990: 77) paraphrases utterance (5c) as, I ask you P because I want to suggest $Q$. This paraphrase, according to Lagerwerf (1998: 22) is misleading for it introduces another speech act 'suggest' which is not included in (5.c).
} 


\subsection{Conceptual-procedural distinction}

According to Blakemore's (2000: 476; 2002: 79) Relevance-based distinction, linguistic constructions encode two basic types of information, namely conceptual information and procedural information. Conceptual information enters into inferential computations, and procedural information constrains these computations by increasing their saliency. Following Blakemore's conceptual-procedural encoding, kubanga PMs can be categorised broadly along two dimensions: those which encode conceptual meaning and those which signal procedural meaning. Kubanga forms at the conceptual level impose constraints on the explicature, thereby contributing to the representational meaning of the utterance. At the procedural level, they impose constraints on conceptual computations thereby guiding the interlocutors in their search for the relevant interpretation (see Blakemore 2002). As mentioned, the cognitive effects associated with kubanga forms are those of presupposition strengthening (see Blakemore 2002). The kubanga form relates propositions in which the information provided by the subordinating clause supports the assumptions described in the main clause.

\section{Kubanga and its position in the utterance}

Studies on PMs had earlier concluded that they are positioned at the periphery/beginning of a discourse unit (see Schiffrin 1987, Schourup 1999). This claim is partly based on Schiffrin's (1987) study where PMs feature on the left periphery of the utterance, appearing syntactically detachable from a sentence. However, later studies have revealed that PMs in general are subject to minimal syntactic restrictions and may occur before, after or between clauses (see Hlavac 2006: 1873; Fischer 2013: 274). However, Heine (2013: 1213) warns that positional flexibility in the placement abilities of PMs does not suggest that PMs can occur anywhere in the discourse. Although PMs may generally be described as free in movement, or positionally mobile, their movement, just like switches, is constrained syntactically and pragmatically (Brinton 2008: 8). Therefore, initiality/positional mobility describes a tendency but not a necessary condition for diagnosing PMs.

In the analysed bilingual data, kubanga forms are also positionally mobile, occupying the initial, medial and final positions as illustrated in utterances (6.a), (6.b) and (6.c), respectively. However, the canonical position of kubanga PMs is medial as illustrated in utterance (6.b).

(6) a. But I think even when I was younger maybe I looked like a responsible child;

$\begin{array}{lllll}\text { kubanga } & n e & a \text {-ba-ntu } & \text { ba-a-leeta-nga } & a \text {-ba-ana } \\ \text { because } & \text { even IV-2-person } & \text { 2-PST-bring-HAB } & \text { IV-2-child } \\ a \text {-wa-ka } & & & \\ \text { IV-16-home } & \text { mainly because I am there }\end{array}$

"But I think even when I was younger maybe I looked like a responsible child because even people used to bring their children at home mainly because I am there." (NJ93).

In this utterance, kubanga occurs initially in order to relate to the adjacent clause. The kubanga clause provides new information which strengthens the presupposition encoded in the previous clause. That is, the information that people used to bring their children to her home provides justification for NJ's thought that she looked like a responsible child. The use of kubanga in 
this utterance is inherently epistemic and therefore subjective. $\mathrm{JN}$ is the responsible subject of consciousness (SoC) whose thought is justifiably represented.

b. Not all of us can be engineers, or medics or language experts but there will always be a community of practice for-for every particular training kubanga it deals with a specific class of problems which problems can only be solved properly, at least, by professionals (KM124).

In this utterance, kubanga occupies a medial position. Like in (6a) above, the causal relations kubanga encodes guide the hearer towards an epistemic interpretation in which KM's opinion about employing professionals is justified by a kubanga-prefaced clause.

In utterance (6c) kubanga occupies a final position to encode implied meaning. This utterance is set in a context in which BG was discussing the challenges of alcoholism for families. The form Eehum is a Luganda interjection interpreted as signalling relief-like agreement (its spelling may be contentious).

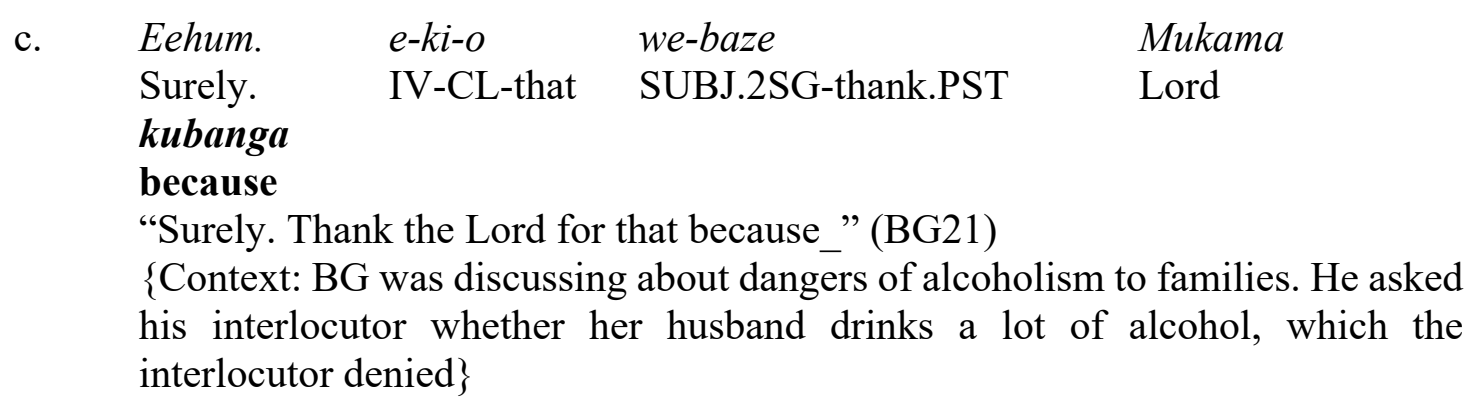

This utterance operates in the speech act domain, in which the active speaker motivates the act he performs using an implicit kubanga 'clause'. The implicit information is expected to be retrieved inferentially from the discourse context and enriched cognitively into a propositional form. Processed in the right context, the derived explicature should relate to the difficulty, challenges, violence and more that she would go through had it been the case that her husband drank. By leaving this information implicit, BG expects his audience to base their interpretation on the contextual information available and infer an explicature. Implicitness also prompts kubanga to be pronounced with a raising intonation pattern (marked with an underscore), a pattern characteristic of incomplete sentences.

In Nakijoba (2018), PMs occupying the final position are described as stand-alone markers. They operate in contexts where the speaker judges that the hearer has easy access to the relevant contextual knowledge from which the implicit meaning can be inferred. Speaker intuition indicates that kubanga forms can only occur finally to direct hearers in processing implicit meaning. By this observation, if the implied meaning encoded by such a kubanga is provided, kubanga can be analysed as occurring medially and the conjoined utterances will receive a comma intonation pattern.

\section{Structural manifestation of kubanga in the data}

In the Luganda-English bilingual data, kubanga forms manifest as core borrowings by motivation and switches by operation. According to Myers-Scotton (2002: 41, 2006: 212-217) 
core borrowing expresses concepts which exist in the lexicon of the replica language/culture. Since they have native lexical equivalents in the replica language, they represent concepts that are not new or foreign. Thus, the speaker's choice to insert an embedded kubanga form in the English Matrix Language (ML) is motivated by factors external to the need to fill a lexical gap given that English (and Luganda) have fully established systems of encoding causality. Similarly, kubanga forms in the bilingual utterances are described as switches because their behaviour in the data conforms to the characteristics of switches, namely, they are not integrated phonologically or morphosyntactically in English, they are not nativised, they do not occur frequently, they lack predictive value, they do not have a dictionary status and thus lack predictive value, and so on (see Poplack and Sankoff (1984)). As switches, kubanga forms occur in the following configurations: i) as single Embedded Language (EL) insertions in the English ML frame, ii) as part of the morphemes forming the EL island, and iii) as elements in the mixed constituencies in classic code-switched clauses, as illustrated below.

\subsection{Kubanga form as a single insertion into English ML}

One of the conversational patterns which describe bilingual speech, according to Auer (2001: 445), is what he describes as Pattern II, metarepresented as, ...A1 [B1] A1... (The letters represent the interacting languages and the numbers represent the interactants). The pattern describes CS behaviour in which a bilingual speaker may introduce an embedded/guest element into the conversation as we see in utterance (7), in which $k u b a$ operates as a switch in the English ML.

$$
\text { Er I think back in } 2002 \text { kuba I was in P.2, ... (AS2) }
$$

\subsection{Kubanga clause as an island}

Kubanga forms can occur as an island which can be an EL or ML island. In utterance (8), it manifests in an EL island and in (9) as an ML island.

$$
\begin{aligned}
& \begin{array}{l}
\text { my problem was school fees; } \begin{array}{l}
\text { kubanga } \\
\text { because }
\end{array} \\
\text { REL-9-S-SUBJ.1SG-PST-be-HAB }
\end{array} \\
& \text { n-noony-a } \\
& \text { SUBJ.ISG-search-FV } \\
& \text { "My problem was school fees. Because that is what I always looked for actually } \\
& \text { not only then but up to when I finished my Bachelors." (LM17) }
\end{aligned}
$$

$\begin{array}{llll}\text { I used before } & o-k u \text {-beera-nga } & m u & \text { office } \\ & \text { IV-INF-be-HAB } & \mathrm{P} & \text { because }\end{array}$

"I used, before \{before KM started farming\}, to be in the office because there was always work to do, Monday to Saturday \{but now KM does not go to office on Saturday, works from Monday to Friday\}." (KM143)

Utterances (8) and (9) comprise a number of clauses. However, my focus is on the kubanga clause operating as an EL island or ML island. In (8), the clause kubanga zennalinga nnoonya (because that is what I always looked for) is an EL island inserted within a larger clause whose ML is English. This means that the morphosyntactic frame of the EL island is defined by Luganda, and its constituents comprise entirely of Luganda morphemes. In (9), the clause "kubanga there was always work to do, Monday to Saturday" represents a constituent in which 
the kubanga clause is an ML island. Within the MLF model, the type of CS in (8) and (9) shows that the participating languages are not in contact.

\subsection{Kubanga in mixed constituents}

Utterance (10) demonstrates classic CS in which the participating languages which contribute to the bilingual clause are in contact. The morphemes that make up the bilingual clause come from Luganda and English, forming mixed constituents. Forms such as estressing $a$ (it stresses), okwattending $a$ (to attend) and oritaking $a$ (you are retaking) by the MOP and the SMP tests, point towards Luganda as the ML. That is, Luganda late system morphemes ${ }^{3}$ are affixed to the English verb form and the derived form conforms to the morpheme order of Luganda as an agglutinative language.

$$
\begin{aligned}
& \text { Retake } \quad e \text {-stressing- } a \text { o-lina } o \text { - } k u \text {-attending- } a \\
& \text { IV-stress-FV SUBJ.2SG-have IV-INF- attend-FV } \\
& \text { lectures } \quad \boldsymbol{k u b a} \quad a \text {-ki-manyi o-ritaking- } a \\
& \text { because SUBJ.3SG-7-know SUBJ.2SG-retake-FV } \\
& \text { o-lin-a o-ku-beera-yo } \\
& \text { SUBJ.2SG-have-FV IV-INF-be-LOC }
\end{aligned}
$$

"Doing a retake paper can be stressful...you have to attend lectures because he/she \{lecturer\} knows that you are a retaking and that you must be there in lectures $\}$. Retaking in Makerere University is the act of resitting for a paper in which a student might have scored below the pass mark." (BN268).

The spelling of the mixed form "oritakinga" (you are retaking) is interesting because it demonstrates that the constraints of CS are powerful enough to trigger structural innovations which may violate the phonotactics of a participating language. In Luganda the alveolar sounds [1] and [r] are allophones of the phoneme /1/. Although they are phonemically indistinguishable, their occurrence is rule governed: / $\mathrm{r} /$ never occurs word initially and when it is used it is preceded by either /e/ or /i/; /1/ is used elsewhere. What we see in "oritaking $a$ " is a justifiable violation of the spelling rules.

\section{Kubanga PMs: Categories and functions}

Kubanga and its forms have been analysed along four categories: the content, epistemic, speech act and metalinguistic domains.

\subsection{Kubanga uses in the content domain [P is a result of $Q$ ]}

As mentioned, kubanga forms at the conceptual level impose constraints on the explicature, thereby guiding the hearer's processing of representational meaning. They signal real-world causal relations between the subordinated clauses, and the relationship they signal will contribute to the truth-conditions of the utterance as we see in utterance (11).

\footnotetext{
${ }^{3}$ Late system morphemes are defined as such because "the lemmas underlying them are not fully salient in language production until the level of the Formulator where larger constituents are assembled" (Myers-Scotton 2002: 76).
} 


\begin{tabular}{|c|c|c|c|c|}
\hline Kati & teacher & $a$-n-jagala & nnyo & kubanga \\
\hline And & HAB & SUBJ.ISG-like-FV & very & because \\
\hline$n-a-l$ & & $n$-performing- $a$ & bulung & \\
\hline SUB & ISG-PST-be & SUBJ.ISG-perform-FV & well & \\
\hline
\end{tabular}

This utterance is set in a context where NC was narrating her relationship with her Science teacher. The utterance operates in the content domain because causality is objectively construed without a responsible SoC. That is, it describes a state of affairs in which the speaker's good performance causes her teacher to like her. What guides the reader to process the real-world causal relations between the two clauses is his encyclopaedic knowledge - the experiential knowledge that students who perform well are usually liked by their teachers. Thus kubanga instructs the hearer to establish a causal interpretation between the main clause "teacher anjagala nnyo" (the teacher liked me very much) and the subordinating clause "nnali mperforminga bulungi" (I used to perform well). The utterance is a mixed constituent comprising Luganda and English morphemes, with Luganda as the ML. If kubanga were to be replaced with an English equivalent such as because, the cognitive effects derived from the utterance would not be any different from the cognitive effects attained when kubanga is used.

\subsection{Kubanga uses in the epistemic domain [because Q, P]}

A mentioned, causality in the epistemic domain is indirect and it concerns the speaker's reasons and justification for what is being described. In utterance (3) (repeated here as 12), what SJ represents is a student's opinion in which it is assumed that the mistakes students make at university are directly attributed to lack of parental guidance. Processing the causal relations between the two utterances requires certain contextual assumptions, which are based on the reader's encyclopaedic knowledge. For instance, the hearer's real world knowledge of the importance of parental guidance as well as their awareness of the possible outcomes of a lack of parental guidance. Against this contextual background, the hearer will be expected to process the two clauses and derive an interpretation in which the claim that students make mistakes is a consequence of the subjective assumption that they lack parental guidance.

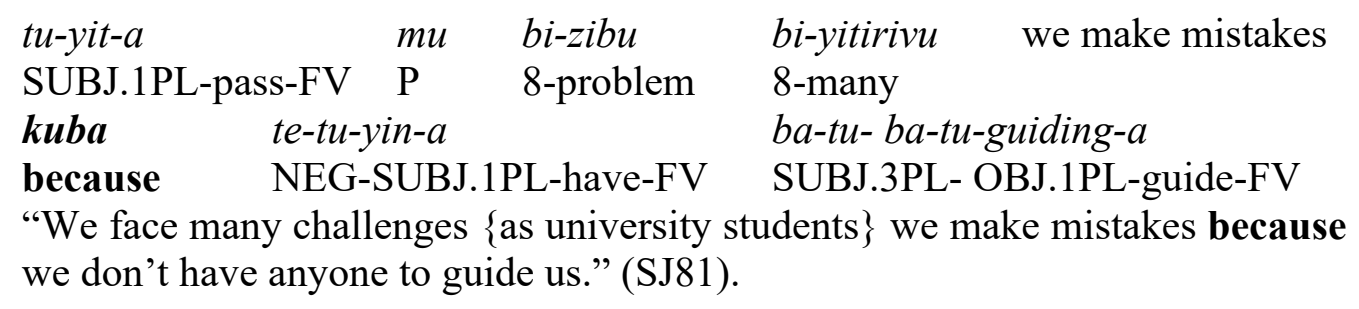

It may be tempting to assume that this utterance operates in the content domain because its interpretation follows what is expected in the real-world causality. What gives it an epistemic interpretation is the fact that it is subjectively construed. Here, the students are speaker SoCs and are directly behind the evaluation and reasoning involved in the causal interpretation.

The utterance is a mixed constituent comprising Luganda and English morphemes, but where Luganda is the ML. First clause "Tuyita mu bizibu bingi" (We go through many challenges) provides preamble-like contextual information, preparing us for the main clause, "we make 
mistakes", which is an EL island consisting of English morphemes. The subordinate clause which hosts a $k u b a$ form, provides a reasons for what is described in the main clause. Kuba instructs the hearer to establish a causal meaning between the clause "we make mistakes" and the clause "tetuyina batuguidinga" (we do not need anyone to guide us).

\subsection{Kubanga in the speech act domain [I Propose/Suggest that P, because Q].}

Speech act causality relates to the speaker's performance of an act and their motivation for it. Like the epistemic domain uses, speech act causality is also subjective and as demonstrated in utterance (13), the active SoC motivates her act on the basis of her observation. That is, the married people praying are motivated by the challenges the marriage institution is faced with.

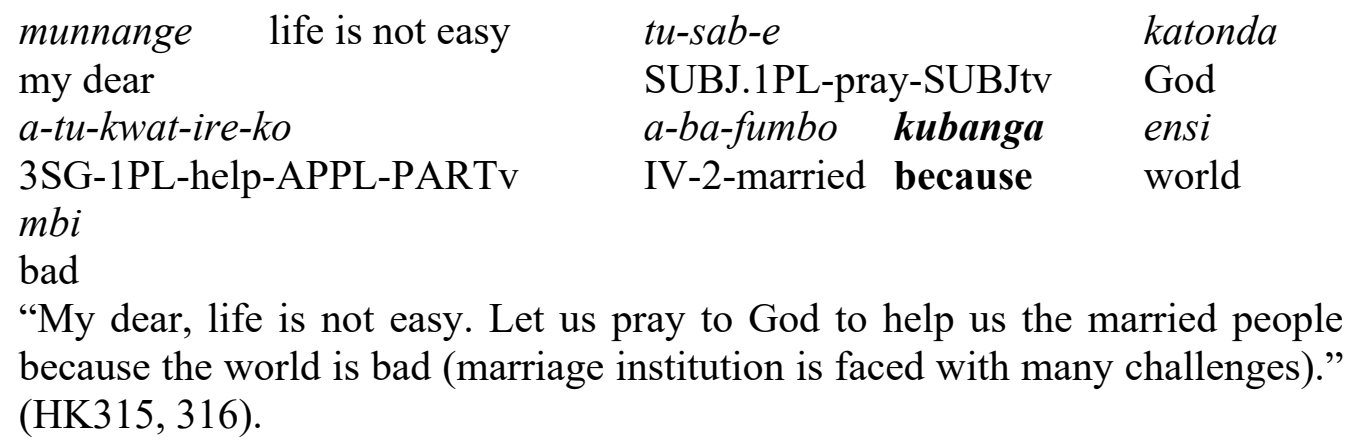

The kubanga clause, kubanga ensi mbi (Lit: because the world is bad), which I describe as operating in the speech act domain, is associated with signalling attitudes and feelings, which according to the speaker requires an action of prayer.

\subsection{Kubanga uses in metalinguistic domain}

In analysing the English connective because operating in three domains (content, epistemic and speech act), Sweetser (1990: 29-30) makes reference to the possibility of causal connectives which operate in more domains. Subsequent studies have empirically illustrated cross-linguistic causal connectives operating in the metalinguistic domain (e.g. Sanders, Sanders and Sweetser 2012). We see that the causal relation in utterance (14) is more conversational than correlational, and it requires a metalinguistic interpretation.

$$
\begin{aligned}
& \text { nti ne e-byo bi-ennyini bi-ba-kos-a } \\
& \text { COMP and 8.DEM 8-exact 8-SUBJ.3PL-affect-FV } \\
& \text { kuba nze bwe n-a-ki-mu-gamb-a } \\
& \text { because I when SUBJ.1SG-PST-7-OBJ.1SG-tell-FV } \\
& \text { na-mu-lab-a nga a-ki-welcominze nnyo } \\
& \text { SUBJ.ISG-PST-OBJ.1SG-see-FV while IV-7-welcome.PST very } \\
& \text { "That sometimes even those things (such as denying them visits) affect them }
\end{aligned}
$$

In the above utterance, two clauses n'ebyo byennyini bibakosa (even those things affect them) and nze bwennakimugamba...(when I told her...) are conjoined with a kuba connective. 
However, when the hearer integrates the conjoined clauses, a direct causal interpretation may not be accessible. Thus, $k u b a$ is construed as a conversational marker signalling transition from one sequence of the narrative to the next. Like in subjective uses, metalinguistic domain also takes a comma intonation pattern.

\section{Domain specificity of kubanga PMs}

A survey of literature shows that languages use certain causal PMs in specific domains (see Maat and Sanders 2000; Sanders, Sanders and Sweetser 2012; Moeschler 2003; Degand and Fagard 2012; Zufferey 2012; Bardzokas 2014). This observation is substantiated by their resistance to interchangeability because they are domain specific. In English, for instance, causality is encoded by markers such as because, since, and for (the reason that), among others. While the different English causal markers can replace others without significant differences in the meaning encoded, as we see in utterance (15), there are contexts and positions in which certain markers are constrained to occur, as illustrated in (16) and (17).

$$
\begin{aligned}
& \text { We needed more time to talk because/since/for the reason that/for we hadn't } \\
& \text { seen each other in ages } \\
& \text { Because/sincelfor the reason that } / \text { *for we had not seen each other in ages, we } \\
& \text { needed more time to talk } \\
& \text { Joy is sad because/?since/for the reason that/?for she misses home }
\end{aligned}
$$

Because as a prototypical causal marker is permissible in all contexts for it is the underspecified PM for encoding the core conceptual and procedural relations. A similar analysis holds in French between the three connectives car, parce que, puisque which relate propositions with backward causal meaning. These too are often not interchangeable; parce que is a 'universal' or default PM, comparable with because and has the ability to operate in all domains. Car predominantly operates in the epistemic and speech act domain, and puisque operates predominantly in echoic usages - interpretations in which the information is known to both the hearer and the speaker (see de Rooij 2000; Moeschler 2003; Degand and Fagard 2012; Zufferey 2012). In addition, studies on Dutch causal connectives (see Maat and Sanders 2000; Sanders, Sanders, and Sweetser 2012) and Modern Greek (see Bardzokas 2014) come to similar conclusions. Interestingly, even within the category of interchangeable markers, there will always be differences in distribution where certain markers occur more frequently than others. These differences can be accounted for in terms of a speaker's linguistic abilities and preferences.

Bringing the kubanga PMs into perspective, I mentioned that kuba/kubanga and olwokuba/olwokubanga are semantically synonymous and can be used interchangeably at the conceptual level to signal representational meaning. However, their resistance to interchangeability when used subjectively points to their domain specificity. It means that there are certain contexts where a kubanga form may be constrained from occurring.

For instance, in signalling implicit meaning in the speech act domain, utterance (13) (repeated here as 18), permits the kubanga form; kuba is questionable; olwokuba and olwokubanga are resisted. 


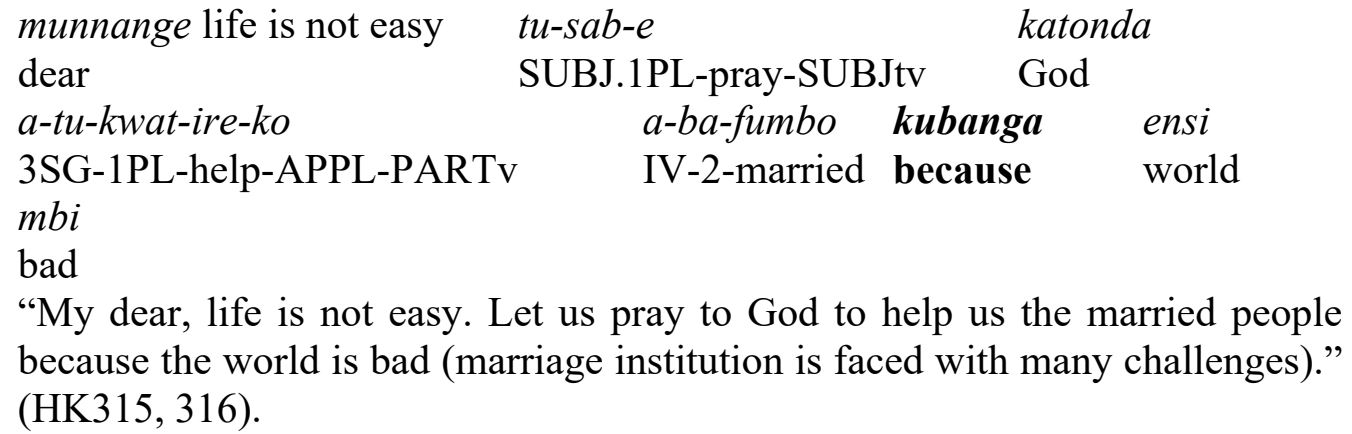

In interrogative utterances such as (19), kubanga and olwokubanga can be interchangeable, olwokuba is questionable and $k u b a$ is unacceptable. In the same way, the Luganda negator $s i$ in (20) can co-occur with only kuba, kubanga is questionable and olwokuba and olwokubanga are resisted.

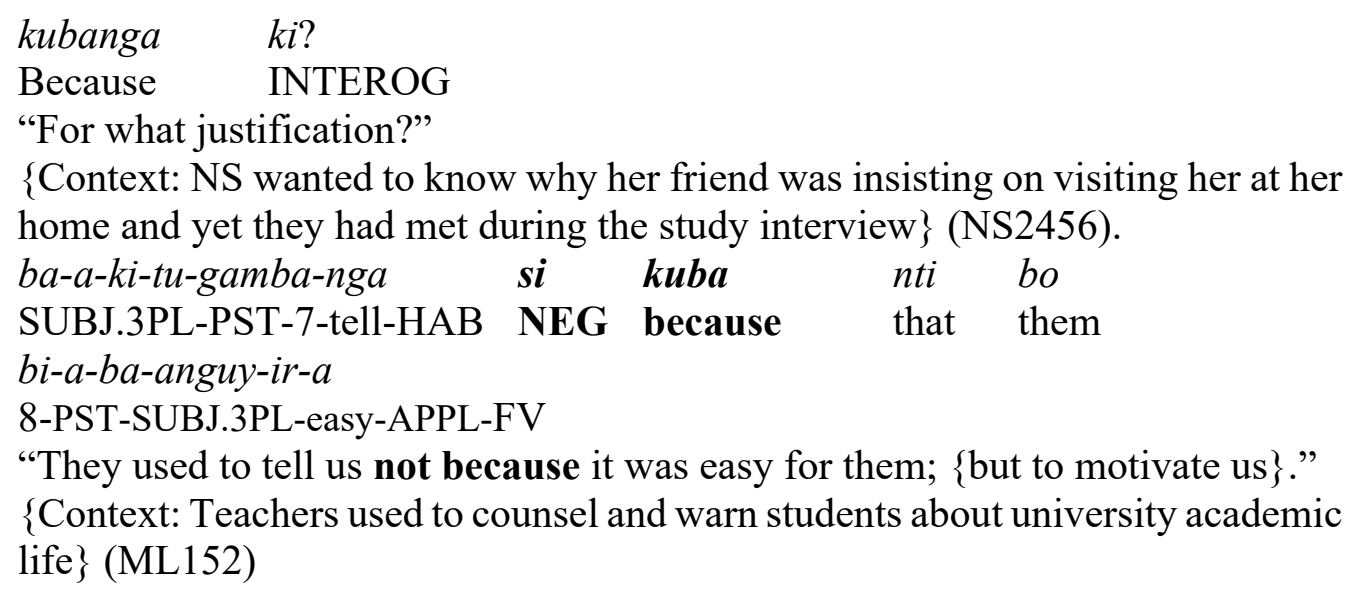

Other than these specialised contexts such as in interrogatives and negated utterances, $k u b a$ and kubanga just like olwokuba/olwokubanga are generally interchangeable. Interestingly, there are utterances such as (21), where both kubanga and kuba are employed, and the two markers can be swapped without causing significant differences in the cognitive effects attained.

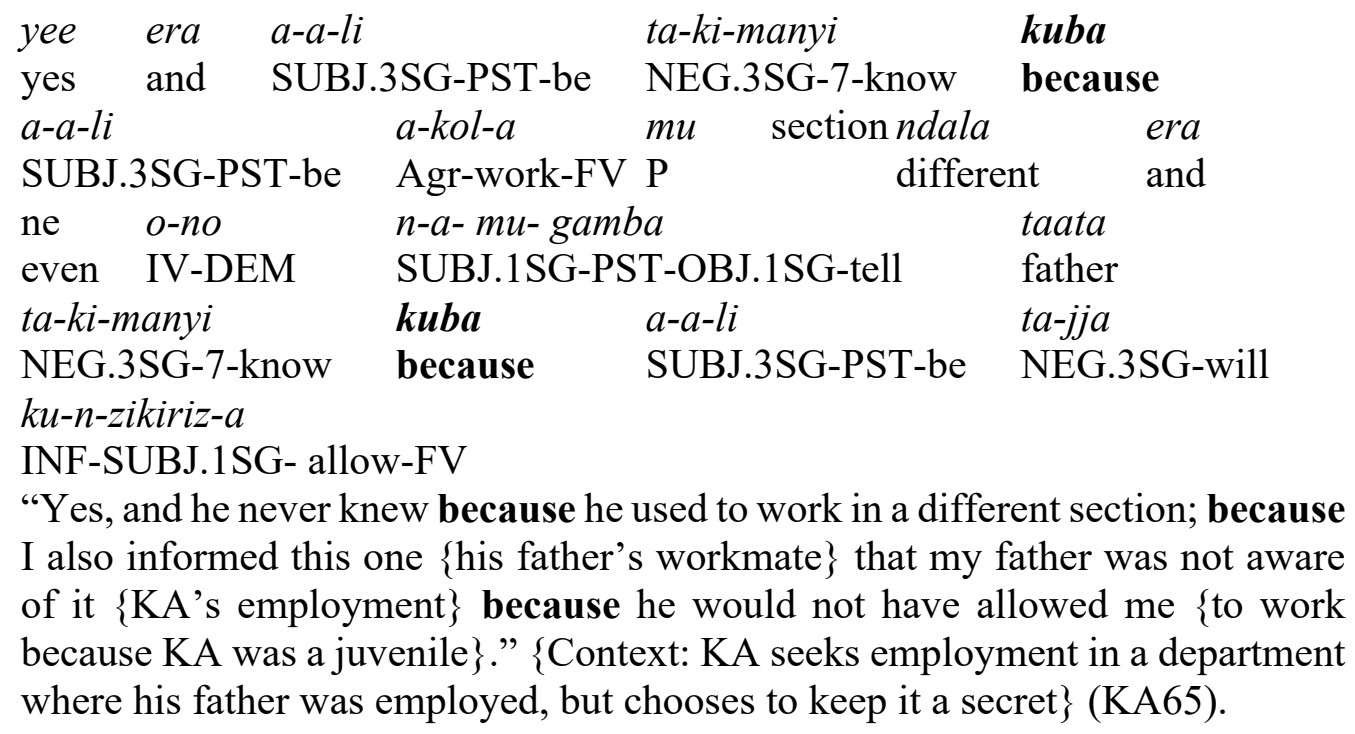


Similarly, in utterances such as (22), olwokubanga can be interchanged with olwokuba without affecting the cognitive effects derived from the utterance.

\author{
It's Buganda olwokubanga it's the centre of so many other tribes... \\ for the reason that \\ \{Context: BM explains why the Buganda tribe may not succeed in preserving \\ its cultural values\} (BM22).
}

Thus, we can say that the speaker's employment of one form over the other where there are no observable rewards in cognitive effects can be best explained in terms of speaker preference. The subject of domain specificity of kubanga forms is interesting but it has not been discussed in details here because this article aims to give a general overview of the manifestation and behaviour of kubanga forms. As I indicate in the following conclusion, the need to study kubanga PMs holistically, and in detail is recommendable.

\title{
8. Conclusion and recommendations
}

In this article, I have analysed the manifestation of kubanga PM forms, partly as conceptual connectives and primarily as procedural markers, and the roles they play in facilitating interaction in bilingual spoken discourse. I pointed out that the kubanga family of causal PMs appear in twelve different shapes: kubanga, kuba, olwokuba, olwokubanga, lwakuba, lwakubanga, kulwokuba, kulwokubanga, okuba, okubanga, bba and bbanga. Out of these, seven forms - kubanga, kuba, olwokuba, olwokubanga, lwakuba, lwakubanga, kulwokuba - are used in the data. I restricted my analysis to only four forms, kubanga, kuba, olwokuba, olwokubanga, which occurred as mixed constituents in the data. In the bilingual clauses where kubanga forms are hosted, they operate as switches, and can occupy the initial, medial and final positions. They may occur as single insertions in the English ML, they can occur as ML or EL islands, and they can manifest in mixed constituents. The analysed data shows that kubanga forms operate objectively and subjectively in the content, epistemic, speech act and metalinguistic domains.

The four analysed kubanga forms are semantically synonymous and can loosely be translated as because at a conceptual level. Although they may be semantically and procedurally related, this discussion has shown that they are not necessarily interchangeable, and their resistance to interchangeability in certain contexts presupposes their domain-specificity. Even in contexts where they may be replaceable, we saw differences in their distribution where speakers had idiosyncratic preferences for a given kubanga form. As mentioned, the notion of domain specificity is not unique to Luganda kubanga PMs as results from cross-linguistic studies, for example, French and Dutch, also attest to it. During the analysis, a number of methodological and theoretical concerns which require further scholarly attention have been raised and they need scholarly attention. The present study being corpus-based, one methodological limitation relates to the size of the corpus, which stands at 192000 words, transcribed from 23 hours of recordings of bilingual conversations with speakers of Luganda and English. The corpus comprised only one mode (spoken text), and only one conversational context (semi-formal interviews and group discussions). Small corpora are less revealing than large corpora featuring multiple contexts and modes. I recommend that a comprehensive analysis based on a larger 
corpus, representative of the different genres and modes of communication, be undertaken for more valid conclusions about Luganda-English PMs in contact. Second, the distribution of PMs in the data is influenced by factors such as the age and gender of participants, and the topic of conversation. However, a discussion of all these factors, interesting as they might be, have not been touched on. Thus, a study which explores the manifestation of these PMs and takes these variables into account would be revealing. Third, the data features many kubanga PMs occurring singly and in monolingual and bilingual combinations. These are not addressed in this article. For a comprehensive analysis of Luganda-English PMs in bilingual spoken discourse, future studies should aim to analyse a wider range of PMs, both synchronically and diachronically. In addition, the interest in studying PM co-occurrences is new and little has been done to explore both monolingual and bilingual PM combinability. Issues with regard to defining combined PMs, determining a concrete label in their reference, establishing what PMs can co-occur, how they co-occur, in what contexts they co-occur, whether the co-occurring PMs are functionally compositional or not, and what constraints bind their combinability, among others, need to be addressed for these are crucial to understanding PMs comprehensively.

\section{Abbreviations}

Agr - agreement; APPL - applied; CP - complementiser phrase; CS - code-switching; DEM demonstrative; EL - embedded language; FV - final vowel; HAB - habitual; INTEROG interrogative; IV - initial vowel; L1 - first language; L2 - second language; LOC - locative; $\mathrm{ML}$ - matrix language; MLF - matrix language frame; MOP - morpheme order principle; OBJ - object; P - preposition; PARTv - partitive; PRF - perfect; PM(s) - pragmatic marker(s); PST - past tense; SG - singular; SMP - system morpheme principle; SoC - subject of consciousness; SUBJ - subject; SUBJtv - Subjunctive; USP - uniform structure principle; 4-M (Model) - four types of morpheme (model).

\section{Transcription symbols}

Single underscore - incomplete utterances, Double underscore-long pause, Hyphentruncation, Dash - lengthened vowel, Asterisk - ill-formedness, Question mark reservations/queries, Ellipsis - incomplete utterance, Curly brackets - enclose contextual information, Capitalisation - emphatic intonation, Double quotes - enclose translations and special expressions, Underline - indicates saliency, Italics - represent Luganda or special expressions in sample excerpts, Bold faced - marks off PMs in the analysed utterances, Codes - refer to speech turns.

\section{References}

Auer, P. 2001. Code switching: Discourse models. In R. Mesthrie (ed.) Concise Encyclopedia of Sociolinguistics. New York: Elsevier. pp. 443-446.

Bardzokas, V. 2014. Linguistic constraints on causal content: The case of Modern Greek markers. Journal of Pragmatics 60: 160-174. https://doi.org/10.1016/j.pragma.2013.11.007 
Blakemore, D. 2000. Indicators and procedures: nevertheless and but. Journal of Linguistics 36: 463-486.

Blakemore, D. 2002. Relevance and Linguistic Meaning: The Semantics and Pragmatics of Discourse Markers. New York: Cambridge University Press. https://doi.org/ $\underline{10.1017 / \text { cbo9780511486456 }}$

Brinton, L. 2008. The Comment Clause in English: Syntactic Origins and Pragmatic Development. Cambridge: Cambridge University Press. https://doi.org/10.1017/ $\underline{\text { cbo9780511551789 }}$

Canestrelli A.R., W.M. Mak and T.J.M. Sanders. 2013. Causal connectives in discourse processing: How differences in subjectivity are reflected in eye movements. Language and Cognitive Processes 28(9): 1394-1413. https://doi.org/10.1080/01690965.2012.685885

Cozijn, R., L.G.M. Noordman and W. Vonk. 2011. Propositional integration and worldknowledge inference: Processes in understanding 'Because' sentences. Discourse Processes: A Multidisciplinary Journal 48(7): 475-500. https://doi.org/10.1080/0163853x.2011.594421

Degand, L. 2000. Causal connectives or causal prepositions? Discursive constraints. Journal of Pragmatics 32: 687-707. https://doi.org/10.1016/s0378-2166(99)00066-1

Degand, L. and B. Fagard. 2012. Competing connectives in the causal domain: French car and parce que. Journal of Pragmatics 44(2): 154-168. https://doi.org/10.1016/j.pragma. 2011.12.009

Fischer, K. 2013. Discourse markers. (n.p). 271-294.

Fraser, B. 1999. What are discourse markers? Journal of Pragmatics 31: 931-952. https://doi.org/10.1016/s0378-2166(98)00101-5

Heine, B. 2013. On discourse markers: Grammaticalisation, pragmaticalisation or something else? Linguistics 51(61): 1205-1247.

Hlavac, J. 2006. Bilingual discourse markers: Evidence from Croatian-English code-switching. Journal of Pragmatics 38(11): 1870-1900. https://doi.org/10.1016/j.pragma.2006.05.005

Lagerwerf, L. 1998. Causal Connectives Have Presuppositions: Effects on Coherence and Discourse Structure. Holland Academic Graphics, Netherlands.

Maat, H.P. and T. Sanders. 2000. Domains of use or subjectivity? The distribution of three Dutch causal connectives explained. In E. Couper-Kuhlen and B. Kortmann (eds.) Cause, Condition, Concession, Contrast: Cognitive and Discourse Perspectives. Berlin: Mouton de Gruyter. pp. 57-82. https://doi.org/10.1515/9783110219043.1.57

Millis, K.K. and M.A. Just. 1994. The influence of connectives on sentence comprehension. Journal of Memory and Language 33: 128-147. https://doi.org/10.1006/jmla.1994.1007 
Moeschler, J. 2003. Causality, lexicon, and discourse meaning. Rivista di Linguistica 15(2): 277-303.

Moeschler, J. 2016. Where is procedural meaning located? Evidence from discourse connectives and tenses. Lingua 175-176: 122-138. https://doi.org/10.1016/ j.lingua.2015.11.006

Muysken, P. 2000. Bilingual Speech: A Typology of Code-mixing. Cambridge: Cambridge University Press.

Myers-Scotton, C. 1993. Duelling Languages: Grammatical Structures in Codeswitching. Oxford: Clarendon Press. https://doi.org/10.1177/003368829502600207

Myers-Scotton, C. 1995. A lexically based model of code-switching. In L. Milroy and P. Muysken (eds.) One Speaker, Two Languages: Cross-disciplinary Perspectives on Codeswitching. Cambridge: Cambridge University Press. pp. 233-256. https://doi.org/10.1017/ $\underline{\text { cbo9780511620867.011 }}$

Myers-Scotton, C. 2002. Contact Linguistics: Bilingual Encounters and Grammatical Outcomes. Oxford: Oxford University Press. https://doi.org/10.1177/13670069050090030201

Myers-Scotton, C. 2006. Multiple Voices: An Introduction to Bilingualism. Malden, MA: Blackwell Publishers.

Myers-Scotton, C. and J.L. Jake. 1995. Matching lemmas in a bilingual language competence and production model: Evidence from intrasentential code switching. Linguistics 33: 981-1024. https://doi.org/10.1515/ling.1995.33.5.981

Nakijoba, S. 2018. Pragmatic Markers in an L1 Luganda-L2 English Spoken Bilingual Discourse: A Relevance Theoretical Approach. PhD dissertation, Stellenbosch University.

Noordman, L.G. and F. de Blijzer. 2000. On the processing of causal relations. In E. CouperKuhlen and B. Kortmann (eds.) Cause, Condition, Concession, Contrast: Cognitive and Discourse Perspectives. Berlin: Mouton de Gruyter. pp. 35-56. https://doi.org/10.25267/ pragmalinguistica.2004.i12.11

Poplack, S. and D. Sankoff. 1984. Borrowing: The synchrony of integration. Linguistics 22: 99-135. https://doi.org/10.1515/ling.1984.22.1.99

de Rooij, V. 2000. French discourse markers in Shaba Swahili conversations. International Journal of Bilingualism 4(4): 447-469. https://doi.org/10.1177/13670069000040040401

Sanders, J., T. Sanders and E. Sweetser. 2012. Responsible subjects and discourse causality. How mental spaces and perspective help identifying subjectivity in Dutch backward causal connectives. Journal of Pragmatics 44(2): 191-213. https://doi.org/10.1016/j.pragma. $\underline{2011.09 .013}$

Sanders, T. and W. Spooren. 2015. Causality and subjectivity in discourse: The meaning and 
use of causal connectives in spontaneous conversation, chat interactions and written text. Linguistics 53(1): 53-92. https://doi.org/10.1515/ling-2014-0034

Schiffrin, D. 1987. Discourse Markers. Cambridge: Cambridge University Press.

Schourup, L. 1999. Discourse markers. Lingua 107(3-4): 227-265. https://doi.org/10.1016/ $\underline{\mathrm{s} 0024-3841(96) 90026-1}$

Stukker, N. and T. Sanders. 2012. Subjectivity and prototype structure in causal connectives: A cross-linguistic perspective. Journal of Pragmatics 44(2): 169-190. https://doi.org/10.1016/j.pragma.2011.06.011

Sweetser, E. 1990. From Etymology to Pragmatics: Metaphorical and Cultural Aspects of Semantic Structure. Cambridge: Cambridge University Press. https://doi.org/10.1017/ $\underline{\mathrm{s} 0022226700000098}$

Zufferey, S. 2012. "Car, parce que, puisque" revisited: Three empirical studies on French causal connectives. Journal of Pragmatics 44(2): 138-153. https://doi.org/10.1016/ j.pragma.2011.09.018

Zufferey, S. 2014. Givenness, procedural meaning and connectives. The case of French puisque. Journal of Pragmatics 62: 121-135. https://doi.org/10.1016/j.pragma.2013.09.022 